\title{
Development of Sheep Butter Based Cream for Dermal Wound Healing
}

\author{
Rai Pratikcha', Das Sujit', Ghosh Tanmoy',*, Deveswaran Rajamanickam², Mohanta Tanmay', Roy Kalyan ${ }^{1}$ \\ 'Department of Pharmaceutics, Himalayan Pharmacy Institute, Majhitar, Sikkim, INDIA. \\ 2Department of Pharmaceutics, Faculty of Pharmacy, MS Ramaiah University of Applied Sciences, Bangalore, Karnataka, INDIA.
}

\begin{abstract}
Objectives: Sheep butter has been traditionally used in the local villages of upper Himalayan region for its various dermatological benefits. In the current study, sheep butter cream was formulated and evaluated for its wound healing properties for the purpose of scientific validation, standardization, safety, efficacy evaluation. Methods: Nine formulations were developed with varying concentrations of ingredients and evaluated for different parameters. Optimized formulations showing neutral $\mathrm{pH}$, good homogeneity and texture, viscosity, spreadability, consistency and antibacterial activity were selected for evaluation of wound healing property in excision wound model and were compared to standard marketed product. Results: From the results obtained, it was observed that formulated creams enabled easy application and removal from the skin without any evidence of irritation, erythema or leftover residue. Amongst all formulations, F-11, F-12 and F-13 showed the most satisfactory properties and were studied in details. Formulations $\mathrm{F}-12$ and $\mathrm{F}-13$ containing $7.5 \mathrm{~g}$ and $10 \mathrm{~g}$ sheep butter respectively
\end{abstract}

were chosen for evaluation of wound healing activity in excision wound model in albino rats. It was noted that on the $15^{\text {th }}$ post-wounding day, F-12 and $\mathrm{F}-13$ showed $94.4 \pm 0.3 \%$ and $96.9 \pm 0.6 \%$ wound contraction respectively, which were found to be significantly higher when compared with the wound contraction of control group $(79.3 \pm 7.5 \%)$ and was comparable with the standard group. Conclusion: Thus sheep butter appears to be effective agent in the management of wound healing activities.

Key words: Antibacterial, Traditional use, Scientific validation, Wound Management, Sheep butter.

Correspondence

Mr. Tanmoy Ghosh

Assistant Professor, Department of Pharmaceutics, Faculty of Pharmacy, MS Ramaiah University of Applied Sciences, Bangalore-560054, Karnataka, INDIA.

Email: tanmoy.ps.ph@msruas.ac.in

DOI: 10.5530/ijpi.2020.1.8

\section{INTRODUCTION}

Sheep butter has been traditionally used in local villages of the upper Himalayan region since many generations for the management of wound, removal of scar, acne and acne scars, reduce lines of wrinkles, brightens skin, making the skin smooth and soft, lightening of lips, pigmentation, trench foot and relieves burning sensation etc. It is also reported to be used in dermatitis and treatment of measles. Sheep butter has an enticing flavour and is adequately rich in Vitamin $\mathrm{A}, \mathrm{B}_{12}$, C, D and E. ${ }^{1}$ Sheep butter is an extract of sheep milk which is also known for its cosmetic, anti-microbial and anti-inflammatory properties. It moisturizes the skin because of the fats present in its butter which helps in reducing the appearance of fine lines and wrinkles. Sheep butter brightens the skin and contains lactic acid, $\alpha$-hydroxy acid (AHA), which is a gentle and natural skin exfoliant. AHAs are well known for its use in the cosmeceutical industry. Sheep buter also reduces redness and breakouts because of the anti-microbial and anti-inflammatory properties as well as protects and repairs skin to preserve and improve the youthful appearance of skin. The high concentration of Vitamins and minerals, especially Vitamin E, also impart antioxidant properties to the butter. ${ }^{2}$ Wounds may be defined as a loss or breaking of cellular and anatomic or functional continuity of the deep skin tissue or the living tissues. ${ }^{3}$ Wounds not only affect the patient physically, emotionally and financially but can also significantly create a scar that may remain on the skin of the patient for the lifetime. ${ }^{4}$ Wounds generally fall in one of two categories; Acute wounds heal within 6 weeks. Chronic wounds, on the other hand, heal at a much slower rate and may take much more than 6 weeks to completely heal up. Wound healing is the bodily response to injury in an attempt to restore normal structure and functioning of the skin. There are four organized phases of wound healing. ${ }^{5,6}$ In Haemostasis phase, we cannot get any blood from the clotted part of wound for stopping the blood flow. ${ }^{7}$ Secondly in, inflammation phase which prevents infection. ${ }^{8}$ Thirdly in, proliferative phase the propagation of new tissues happened and new blood vessels are created with new networking system..$^{8}$ And lastly in, maturation phase also called the remodelling stage wherein wound is totally cleared and apoptosis, programmed cell death happens.

In the current study, sheep butter cream was formulated and evaluated for its wound healing properties for the purpose of scientific validation, standardization and safety and efficacy evaluation.

\section{MATERIALS}

Sheep butter was procured from villagers of Teshingdang, an upper Himalayan village in Sikkim. Yellow beeswax, Glycerol mono stearate, liquid paraffin, hard paraffin was purchased from SD fine chemicals, Mumbai and was of pure grade. All other chemicals and polymers purchased were of analytical grade.

\section{METHODS}

\section{Preliminary investigation of sheep butter}

The initial investigation of sheep butter was carried out in terms of its appearance, colour, odour, melting point, saponification value etc.

\section{Melting point determination}

For the determination of melting point, $0.5 \mathrm{G}$ butter was transferred to a test tube and the test tube was then placed in a beaker containing 50 
$\mathrm{ml}$ of water and the beaker was then placed over a Bunsen burner. A temperature probe was placed to record the heat required to initiate the melting of the butter.'

\section{Saponification Value}

In the determination of saponification value, accurately weighted $2 \mathrm{gm}$ of butter was transferred to $200 \mathrm{ml}$ flask and into it $25 \mathrm{ml}$ of ethanol was added to solubilize the butter. Then excess of $\mathrm{KOH}$ was added and refluxed on water bath for hydrolysis of the butter. The excess of $\mathrm{KOH}$ was then estimated by titration method against $0.5 \mathrm{M} \mathrm{HCL}$ (a ml) using phenolphthalein solution as an I ndicator. This was then compared with blank determination omitting the butter which was under examination (b ml). ${ }^{10}$

$$
\text { Saponification value }=28.05(\mathrm{~b}-\mathrm{a}) / \mathrm{w}
$$

\section{Formulation of sheep butter cream}

Nine different creams was prepared by melting the waxes as given in Table 1 in a china dish according to their decreasing melting point so that the wax/fat with least melting point does not get charred due to overheating. During same time all the water miscible ingredients including the preservatives were also heated to almost same temperature and then aqueous mixture was gradually mixed with melted waxes in a china dish with continuous stirring until a waxy cream base was formed. During this time perfume i.e. Rose oil and Vitamin $\mathrm{E}$ was also added to the cream.

\section{Characterization of sheep butter creams Physical properties}

All the developed creams were examined for their organoleptic properties namely colour, odour, appearance and texture. ${ }^{11,12}$

\section{Determination of $\mathrm{pH}$, homogeneity and texture}

$\mathrm{pH}$ of each cream was recorded using digital $\mathrm{pH}$ meter (Beckman, Germany). It was carried out by dissolving $0.5 \mathrm{G}$ of each in $50 \mathrm{ml}$ of distilled water at $25^{\circ} \mathrm{C}$ and then by bringing the diluted cream in direct contact with $\mathrm{pH}$ meter. After this, $\mathrm{pH}$ meter was allowed to equilibrate and then $\mathrm{pH}$ is recorded. ${ }^{13,14}$ The feel effect of creams was tested by placing each base of cream in between thumb and finger to check their stiffness and greasiness. ${ }^{15}$

\section{After feel effect and Ease of removal}

The emollient property of the creams were tested which is also called as after feel effect testing. ${ }^{16}$ In this test $1 G$ of each formulations were weighed accurately and applied over an area of 2 sq. inch to intact skin on the back of hand and were checked for their softening or soothing properties, slipperiness and leftover residue after application. The removability of cream from skin and cloths were determined by placing a little amount of cream bases under water. ${ }^{17}$

\section{Viscosity and Spreadability}

Viscosity of each cream base was determined using Brookfield viscometer DVII with spindle No $64.50 \mathrm{G}$ cream bases were placed in a beaker and the spindle was partially immersed in the cream and allowed to rotate at $10 \mathrm{RPM}$ at room temperature. ${ }^{18}$ To measure the spreadability of the cream bases, modified apparatus was manufactured in-house. It consists of a wooden block and a pair of glass slides. Approximately, 2 $\mathrm{G}$ of developed cream bases were placed in the lower fixed slide. Then the upper movable slide was placed over the lower fixed slide and subsequently weight was attached to a hook which was tied to the upper slide. The time taken by upper slide to separate completely from the fixed slides was noted. ${ }^{19}$ The gel spreadability was evaluated through following equation: $S=\mathrm{ML} / \mathrm{T}$

Where $\mathrm{S}$ = spreadability, $\mathrm{M}$ = weight tied to upper slide, $\mathrm{L}=$ length of glass slide and $\mathrm{T}=$ time taken by the slide to separate from.

\section{Primary Skin irritation study}

The skin irritation study was carried out in accordance to OECD 404 Guidelines. Three healthy male albino New Zealand rabbits weighing between $2-2.5 \mathrm{~kg}$ was selected for the study. Each rabbit will be caged individually and food and water will be given ad libitum. Twenty four hour prior to study hairs from the back of each rabbit will be shaved off to expose sufficiently large test area for the creams. Just before the study test sites will be wiped off with alcohol and creams ( $1.5 \mathrm{~g}$ each) were applied to their skin. The site will be covered with a gauze patch for up to four hours, after which the creams were removed and remaining substance (if any) wiped away. The test sites were checked for next $24 \mathrm{hr}$ for erythema, edema, ulcers, bleeding and bloody scabs. ${ }^{20}$

\section{Moisture absorption study}

$5 \mathrm{~g}$ of each developed formulations were placed on a petri dish and kept in a desiccator along with a beaker containing water. The desiccator was left undisturbed for $24 \mathrm{hr}$. After the test period, the creams were reweighed to check any gain in weight. ${ }^{21}$

\section{Stability study}

Stability study is one of the major parts of development of any kind of formulation. This study reflects the half-life, conditions of storage and expiry dates of the developed creams. Further it is a requirement for regulatory bodies for approval of any formulation. For this accelerated stability studies were carried out on the optimized formulations to determine the stability of the creams. ${ }^{22}$

\section{Antibacterial study}

Antibacterial properties of the formulations were monitored against $E$. coli (Gram negative bacterial) and Staphylococcus aureus (Gram positive bacteria). Cultures of each of the microbes containing $10^{8} \mathrm{CFU} / \mathrm{ml}$ was prepared and cultured at $37^{\circ} \mathrm{C}$ in an incubator. Disc diffusion method was used to evaluate the antimicrobial activities. In this, the specimens were prepared by dipping the circular discs of paper (10 $\mathrm{mm}$ diameter) in each of the creams and then placed on the nutrient agar plate. A control without any formulation was also placed along with a standard (Soframycine by Sanofi containing Framycitine Sulphate IP 1\%). After incubation for $24 \mathrm{hr}$ in an incubator at $37^{\circ} \mathrm{C}$, the diameter of zone of inhibition was measured in terms of diameter $(\mathrm{mm}) .^{23}$

\section{In-vivo wound healing study in excision wound model}

The wound healing potential of formulation code F-12 and F-13 was analyses using animal model. Female albino rats weighing approximately $200 \pm 20 \mathrm{~g}$ were left for two days at room conditions for acclimatization. A standard pallet diet and water ad libitum was maintained throughout the experiment. A minimum of five rats were used in each groups as well as for standard formulation (Framycitine Sulphate IP 1\%) and disease control. The study was approved by Institutional animal ethics committee and the experiment was performed according to the guidelines issued by Committee for Purpose of Control and Supervision of Experiment on Animals (CPCSEA) India [Registration no:1028/C/07/CPCSEA]. All animals were anaesthetized by intra muscular injection of Ketalar. ${ }^{24-26}$ The hairs on the skin of animals were removed and disinfected using ethanol. ${ }^{27,28}$ Then area of wound to be produced was marked with a circular stainless-steel stencil on the dorsal thoracic region on the back of the rats with methylene blue. Using toothed forceps and pointed scis- 
sors, a circular fragment $\left(300 \mathrm{~mm}^{2}\right.$ in area) in length and $0.2 \mathrm{~cm}$ depth of total thick skin was excised. The day of injury was known as Day 0. The wound size was measured using transparent papers and a permanent label on day $0,5,10,15$ and 20. A graph paper was used to calculate the wound areas to assess changes in the healing of wound. The time taken to epithelialize was measured in days required to fall the eschar without leaving behind any residual raw wound. ${ }^{29}$

Wound healing rate was expressed as:

$$
\% \text { of wound closure }=\frac{\text { Wound area on day } 0-\text { wound area on day n }}{\text { Wound area on day } 0} \times 100
$$

Where, $n=$ number of days.

\section{Statistical analysis}

The experimental data were expressed in mean \pm standard error of mean (SEM). The statistical significance was analysed using one-way analysis of variance (ANOVA) followed by Dunnett compare all column vs. control column. Difference between groups was considered significant at $P$ $<0.05$ levels. $^{30}$

\section{RESULTS}

\section{Analysis of the active ingredient (Sheep Butter)}

Results of physical and chemical analytical tests of sheep butter are depicted in Table 2 which gives an insight into several properties of the active ingredient being investigated. Since sheep butter traditional values were not found in literature therefore its experimental values could not be compared with the literature values.

\section{Characterization of the sheep butter creams Physical properties}

All formulations under investigation i.e. F-11 through F-19 were checked for their colour, odour, appearance and consistency. Upon examination, all of the formulations were found to have acceptable properties. Results of the tested parameters are specified in Table 3 and best formulations images are displayed in Figure 1 (F11 to F13).

\section{Determination of $\mathrm{pH}$, homogeneity and texture}

$\mathrm{pH}$ of the developed creams were determined using digital $\mathrm{pH}$ meter. According to the outcomes obtained, formulation F-17, F18 and F-19 showed slightly alkaline $\mathrm{pH}$ which may cause irritation to the skin. Formulations F-11 to F16 showed nearly neutral pH which may be attributed to the lesser concentration of hard paraffin and yellow bees wax.
This may be attributed to the increase concentration of waxes, which may turn the $\mathrm{pH}$ of the cream towards alkaline side. On the basis of results obtained formulation code F-17 to F-19 were not used thereafter as creams with alkaline $\mathrm{pH}$ may cause irritation to the wound bed causing discomfort to the patients.

Formulations F-11 to F-16 were further characterized for their homogeneity and texture by taking a small sample of the creams between thumb and index finger and rubbing the fingers to check for any grittiness or roughness. F-11, F-12 and F-13 formulations demonstrated homogeneity with no gritty feeling when rubbed between fingers. F-14 to F-16 was found to be gritty with heterogeneity and whitening effect on the applied area. This whitening effect can be attributed to the slightly higher quantities of waxes and thus these formulations were evaluated for further studies.

\section{After-feel effect and Ease of removal}

The formulations F-11 to F13 displayed good emollient properties, were slightly slippery when applied to the skin surface and did not leave any residues after application.

In continuation to the after feel effect test, cream applied part of the skin was washed with tap water to check the ease with which creams can be removed from the skin without leaving behind any residues or greasiness. It was observed that all the investigated formulations (F-11, F-12 and F-13) were easily removed from the skin upon washing and left behind no residues or greasiness.

\section{Viscosity and Spreadability}

Viscosity of formulations F-11 to F 13 was carried out using Brookfield viscometer and the results are shown in Table 4. The results showed optimum viscosity of all the three formulations which infers that these can be easily applied to the skin with minimum efforts. The spreadability

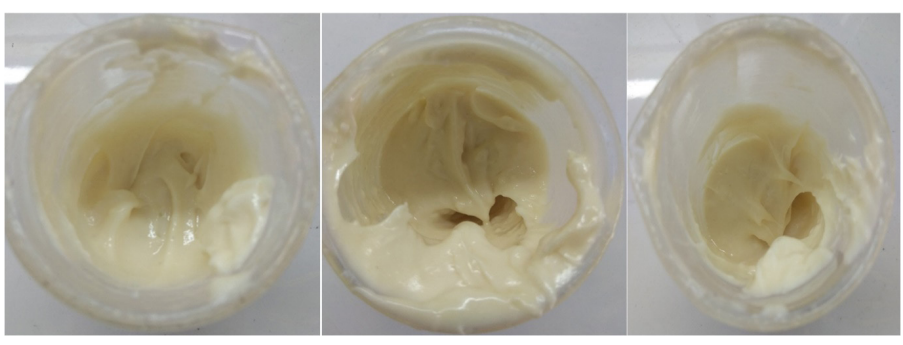

Figure 1: Formulation of creams F-11, F-12, F-13.

Table 1: Ingredients used for preparation of formulations F11-F19.

\begin{tabular}{|c|c|c|c|c|c|c|c|c|c|}
\hline Ingredients & F11 & F12 & F 13 & F14 & F15 & F16 & F17 & F18 & F19 \\
\hline Sheep butter (g) & 5 & 7.5 & 10 & 5 & 7.5 & 10 & 5 & 7.5 & 10 \\
\hline Yellow beeswax (g) & 2.5 & 2.5 & 2.5 & 3 & 3 & 3 & 3.5 & 3.5 & 3.5 \\
\hline Glyceryl monostearate (g) & 1.5 & 1.5 & 1.5 & 1.5 & 1.5 & 1.5 & 1.5 & 1.5 & 1.5 \\
\hline Propyl paraben & 0.05 & 0.05 & 0.05 & 0.05 & 0.05 & 0.05 & 0.05 & 0.05 & 0.05 \\
\hline Span-80 (ml) & 4 & 4 & 4 & 5 & 5 & 5 & 6 & 6 & 6 \\
\hline Light liquid paraffin (ml) & 15 & 15 & 15 & 18 & 18 & 18 & 15 & 15 & 15 \\
\hline Vitamin E (ml) & 0.4 & 0.4 & 0.4 & 0.4 & 0.4 & 0.4 & 0.4 & 0.4 & 0.4 \\
\hline Rose oil (ml) & 2 & 2 & 2 & 2 & 2 & 2 & 2 & 2 & 2 \\
\hline
\end{tabular}


Table 2: Organoleptic properties of sheep butter.

\begin{tabular}{ccc}
\hline SI. no. & Test Parameters & Results \\
\hline 1 & Colour & Off-white to pale yellow color \\
2 & Odour & Strong characteristic smell of butter \\
3 & Melting point & $40^{\circ}-42^{\circ} \mathrm{C}$ \\
4 & Saponification value & 476.85 \\
\hline
\end{tabular}

Table 3: Organoleptic properties of formulated creams.

\begin{tabular}{|c|c|c|c|c|c|}
\hline $\begin{array}{c}\text { Formulation } \\
\text { Code }\end{array}$ & Color & Odor & Appearance & Consistency & $\mathrm{pH}$ \\
\hline F-11 & $\begin{array}{l}\text { Off- } \\
\text { white }\end{array}$ & Pleasant & Semi-solid & Smooth & 7.328 \\
\hline F-12 & $\begin{array}{l}\text { Off- } \\
\text { white }\end{array}$ & Pleasant & Semi-solid & Smooth & 7.262 \\
\hline F-13 & $\begin{array}{l}\text { Off- } \\
\text { white }\end{array}$ & Pleasant & Semi-solid & Smooth & 7.645 \\
\hline F-14 & $\begin{array}{l}\text { Off- } \\
\text { white }\end{array}$ & Pleasant & Semi-solid & Smooth & 7.658 \\
\hline F-15 & $\begin{array}{l}\text { Off- } \\
\text { white }\end{array}$ & Pleasant & Semi-solid & Smooth & 7.613 \\
\hline F-16 & $\begin{array}{l}\text { Off- } \\
\text { white }\end{array}$ & Pleasant & Semi-solid & Smooth & 7.936 \\
\hline F-17 & $\begin{array}{l}\text { Off- } \\
\text { white }\end{array}$ & Pleasant & Semi-solid & Smooth & 8.654 \\
\hline F-18 & $\begin{array}{l}\text { Off- } \\
\text { white }\end{array}$ & Pleasant & Semi-solid & Smooth & 8.676 \\
\hline F-19 & $\begin{array}{l}\text { Off- } \\
\text { white }\end{array}$ & Pleasant & Semi-solid & Smooth & 8.833 \\
\hline
\end{tabular}

Table 4: Viscosity values of formulations

\begin{tabular}{ccc} 
Formulation & Viscosity (in cps) & Spreadability (g.cm/sec) \\
\hline F-11 & 19740 & 14.48 \\
F-12 & 22330 & 13 \\
F-13 & 24600 & 11.53 \\
\hline
\end{tabular}

studies of these formulations were carried out using modified spreadability apparatus and it was observed that F-11 possessed slightly better spreadability properties than the other two formulations.

\section{Primary Skin irritation study}

The primary skin irritation study of formulations F-11, F-12 and F-13 showed no signs of irritation on rabbit skin. There were no signs of itching, swelling, discomfort, erythema on the applied part of the skin and thus the tested samples passed the skin irritation study.

\section{Moisture absorption study}

Moisture absorption study after keeping the creams for $24 \mathrm{hr}$ in with a beaker of water in a desiccator showed almost no difference in weight. This infers that the creams F-11 to F-13 were non hygroscopic in nature.

\section{Stability studies}

Formulations F-11, F-12 and F-13 were subjected to accelerated stability testing $\left(40^{\circ} \mathrm{C} \pm 2{ }^{\circ} \mathrm{C} / 75 \% \mathrm{RH} \pm 5 \% \mathrm{RH}\right.$ for six months) following which they were checked for any phase separation, change in colour or odour, homogeneity. It was noted that all three formulations passed the test with no significant changes.

\section{Anti-bacterial study}

The formulations F-11, F-12 and F13 were evaluated for their antibacterial activity against gram positive (Staphylococcus aureus) and gramnegative bacteria ( $E$. coli). The zone of inhibition results are given in Table 5 which exhibited that Formulation F-11 showed negligible zone of inhibition as compared to control in both gram positive and gram negative microbes. Zone of inhibition of F-12 and F-13 are comparable with standard cream (Soframycine cream). This attribute may be related to the higher concentration of sheep butter in these formulations.

\section{Evaluation of wound healing activity in excision wound model}

Excision wound model was carried out on rats as shown in Figure 2 and the wound contraction at different time intervals till complete wound healing was measured. Table 6 depicts the effects of topical application of F-12, F-13 cream variants on percentage wound contraction in excision wound model. F-13 showed a remarkable percentage wound contraction in comparison to normal control group

\section{DISCUSSION}

The course of wound healing mainly consists of two components, Firstly, formation and migration of new cells to wound bed and secondly, protecting wound bed from microbial load during the wound healing process. With this objective in mind traditional use of sheep butter for

Table 5: Antibacterial activity of the formulation.

\begin{tabular}{ccc}
\hline Test organism & \multicolumn{2}{c}{ Zone of inhibition in $\mathrm{mm}$} \\
\hline E. coli & Standard & $17 \mathrm{~mm}$ \\
& Control & $10 \mathrm{~mm}$ \\
F-11 & $10.5 \mathrm{~mm}$ \\
F-12 & $12 \mathrm{~mm}$ \\
Ftaphylococcus aureus & Standard & $16 \mathrm{~mm}$ \\
& Control & $16 \mathrm{~mm}$ \\
& F-11 & $10 \mathrm{~mm}$ \\
& F-12 & $10 \mathrm{~mm}$ \\
& F-13 & $13 \mathrm{~mm}$ \\
\hline
\end{tabular}

Table 6: Effects of F-12 and F-13 on \% wound contraction on animal models.

\begin{tabular}{ccccc}
\hline Group & \multicolumn{2}{c}{$\%$ wound contraction in different days } & $\begin{array}{c}\text { Epithelialization } \\
\text { period (days) }\end{array}$ \\
\cline { 2 - 4 } & 5 Day & 10 Day & 15 Day & $20 \pm 2$ \\
\hline Control & $12.01 \pm 1.9$ & $49.4 \pm 3.7^{* * *}$ & $79.3 \pm 7.5^{* * *}$ & $13.2 \pm 0.64^{* * *}$ \\
Standard & $26.4 \pm 2.7^{* * *}$ & $86.3 \pm 6.3^{* * *}$ & $97.6 \pm 0.6^{* * *}$ & $14.6 \pm 0.48^{* * *}$ \\
Test 1 & $22.1 \pm 2.4^{* * *}$ & $75.8 \pm 4.9^{* * *}$ & $94.4 \pm 0.3^{* * *}$ & $13.9 \pm 0.64^{* * *}$ \\
$\begin{array}{l}\text { (F-12) } \\
\text { Test 2 }\end{array}$ & $24.5 \pm 2.09^{* * *}$ & $80.2 \pm 6.7^{* * *}$ & $96.9 \pm 0.6^{* * *}$ & 13. \\
(F-13) & & & & \\
\hline
\end{tabular}




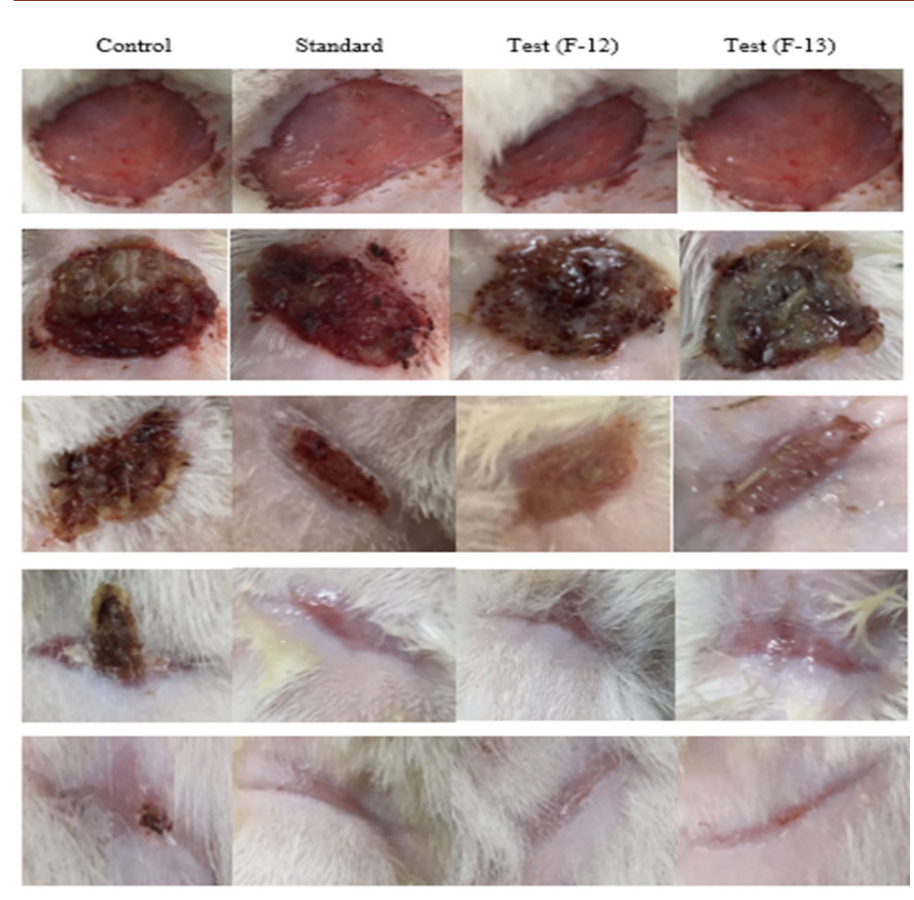

Figure 2: Representative images of wounds in excision model in rats. Row 1 indicates wounds on Day 0; Row 2 indicates wounds on Day 5; Row 3 indicates wounds on Day 10; Row 4 indicates wounds on Day 15 and Row 5 indicates wounds on Day 20.

wound management was scientifically investigated and couple of formulations with different concentration of sheep butter was developed as minimum concentration of dose of sheep butter for wound healing was not known and was reported in literature. Although cows ghee has been traditionally used as a wound healer from ancient days and is been reported several times in literature but no work is published on use of butter for the same effect till date. ${ }^{31}$ The basis of the study was based on the fact that although antibacterial activity is needed in a formulation for faster healing but its part is only limited to safeguarding the wound from bacterial contamination whereas the deposition and /or stimulation of external growth factors which are required during healing process for cell migration, adhesion, stimulation and proliferation are the most essential part of wound healing profile..$^{32}$ The presence of several saturated and unsaturated fatty acids in milk products like ghee and butter which takes part in metabolic processes involved in healing may have contributed to the wound healing potential of sheep butter. ${ }^{33}$ Creams were the obvious choice for our formulation as it is the most convenient form of topical application. Parameters for deciding suitability of a cream includes $\mathrm{pH}$, viscosity, spreadability and consistency. Careful examination of these important parameters suggested that few formulations were not suitable for topical application and were discarded. Outcomes of skin irritation study were encouraging as three formulated creams (F-11 to F-13) were not showing any signs of irritation, itching or swelling at the site of application. Similar indications were also apparent from the results of antibacterial study when compared to standard marketed formulation. The results summarized that although the antibacterial action of formulation F 12 and F 13 were comparable with standard but F-11 fails to show antibacterial action and thus was left out of in-vivo studies. Wound analysis by excision wound model in rats reveals that all groups showed a decrease in wound area from day to day. On the $15^{\text {th }}$ post-wound day, the control group showed $79.3 \pm 7.5 \%$ wound contraction whereas standard, Test 1 (F-12) and Test 2 (F-13) groups showed 97.6 $\pm 0.6 \%, 94.4 \pm 0.3 \%$ and $96.9 \pm 0.6 \%$ wound contraction respectively. The wound closure time taken for the final optimized formulations were significantly lower than control group from $5^{\text {th }}$ day onwards. All the readings are found to be statistically significant and comparable with the standard group. The epithelialization time i.e. the time at which complete scar formation occurs suggest that the developed formulations, was found to be significant and comparable with standard. Complete epithelialization of wound in case of control group was found to be $20 \pm 2$ days, for Test 1 and Test 2 was $14.6 \pm 0.48$ days and $13.9 \pm 0.64$ days respectively. From the formulations selected for animal studies, F-13 showed better wound healing activity and could be further analysed for its safety efficacy and potential.

\section{CONCLUSION}

In this study, traditional use of sheep butter as a wound healing agent was scientifically investigated and validated using experimental studies. The results showed the antibacterial as well as promotion of wound healing activity of sheep butter may be due to incorporation of growth factors as well as presence of Vitamins required for cell adhesion, multiplication and proliferation at the wound bed. Although additional parameters are needed to be evaluated such as cytotoxicity study, haemolytic study, antioxidant studies etc. To determine the safety and efficacy of sheep butter completely, but this work in a stepping stone towards validating the traditional use of sheep butter as a wound management agent by the upper Himalayan tribes of India.

\section{ACKNOWLEDGEMENT}

The authors are thankful to Himalayan Pharmacy Institute, East Sikkim, India for allowing us to use their facilities for the completion of the research work.

\section{CONFLICT OF INTEREST}

No conflict of interest between the authors.

\section{ABBREVIATIONS}

G: Gram; KoH: Potassium hydroxide; CFU: Colony forming units.

\section{REFERENCES}

1. Balthazar CF, Pimentel TC, Ferrão LL, Almada CN, Santillo A, Albenzio M, et al. Sheep Milk: Physicochemical Characteristics and Relevance for Functional Food Development. Compr Rev Food Sci Food Saf. 2017; 16(2):247-62.

2. El-Salam MHA, El-Shibiny S. Bioactive Peptides of Buffalo, Camel, Goat, Sheep, Mare and Yak Milks and Milk Products. Food Rev Int. 2013;29(1):1-23.

3. Gonzalez AC, Costa TF, Andrade ZD, Medrado AR. Wound healing-A literature review. Anais Brasileiros De Dermatologia. 2016;91(5):614-20.

4. Percival NJ. Classification of wounds and their management. Surgery 2002;20(5):114-7.

5. Wallace HA, Basehore BM, Zito PM. Wound Healing Phases. In: StatPearls, Treasure Island (FL): StatPearls Publishing. 2020.

6. Guo SA, DiPietro LA. Critical review in oral biology and medicine: Factors affecting wound healing. J Dent Res. 2010;89(3):219-29.

7. Saghazadeh S, Rinoldi C, Schot M, Kashaf SS, Sharifi F, Jalilian E, et al. Drug delivery systems and materials for wound healing applications. Advanced Drug Delivery Reviews. 2018;127:138-66.

8. Sami DG, Heiba HH, Abdellatif A. Wound healing models: A systematic review of animal and non-animal models. Wound Med. 2019;24(1):8-17.

9. Stemmle DM. Compound Butter Sauce. US Patent Application number: $11 / 379,212,2006$

10. Pharmacopoeia I. Government of India, ministry of health and family welfare Delhi: Controller of Publications. 1996;2:A117-24.

11. Rani S, Singh N, Gautam SP, Kaur S. Formulation, optimization and evaluation of dendricream for wound healing activity of Artemisia indica. WJPPS. 2016;5(8):1483-97.

12. Saheb SKU, Reddy AP, Rajitha K, Sravani B, Vanitha B. Formulation and evaluation of cream from naturally containing plant extracts. WJPPS. 2018;7(5):85162.

13. Pandey S, Seth A, Tiwari R, Singh S, Behl HM, Singh S. Development and evalu ation of antimicrobial herbal cosmetic preparation. Afr J Pharm Pharmacol. 2014;8(20):514-28

14. Alobaidi AH, Hamad ES, Kudair KA, Alsamarai AM. Formulation of Hypopigmen- 
tation Cream and Evaluation of its Effect on Skin Pigment. Part I: Formulation of the Product. Our Dermatology Online. 2014;5(1):9.

15. Wiegand $\mathrm{C}$, Abel M, Ruth $\mathrm{P}$, Elsner $\mathrm{P}$, Hipler UC. pH influence on antibacterial efficacy of common antiseptic substances. Skin Pharmacol Physiol. 2015;28(3): 147-58

16. Gupta N, Dubey A, Prasad P, Roy A. Formulation and evaluation of herbal fairness cream comprising hydroalcoholic extracts of Pleurotusostreatus, Glycyr rhiza glabra and Camellia sinensis. UK J Pharm Biosci. 2015;3(3):40-5.

17. Muthukumarasamy R, Ideris NA. Formulation and evaluation of antioxidant cream containing methanolic extract of Piper betel leaves. Int J Pharm Bio Sci. 2016;7(4):323-8

18. Himaja N. Formulation and Evaluation of Herbal Cream from Azadirachta indica Ethanolic Extract. IJournals: Int J Res Drug Pharm Sci. 2017;1(1):23-6.

19. Nair SS, Mathew M, Sreena K. Formulation and evaluation of herbal cream containing Curcuma longa. Int J Pharm Chem Sci. 2012;4:1362-8.

20. Lokesh PMS, Gurunath KP, Chandrasekar SB, Umashankar C, Pawar AT. Formulation and evaluation of herbal formulations (Ointment, Cream, Gel) containing Tridaxprocumbens and Areca catachu. J Sci Innov Res. 2017;6(3):97-100.

21. Karemore MN, Charde YM, Dharmadhikari P, Bhise SM. Formulation and evaluation of a moisturizing cream using almond butter. Int J Pharm Sci Drug Res. 2017; 9(3):105-22.

22. Gade J, More S, Bhalerao N. Formulation and characterization of herbal cream containing Fenugreek seed extracts. Int J Sci Res. 2015;5:1-4.

23. Rasheed A, Shama SN, Joy JM, Reddy BS, Roja C. Formulation and evaluation of herbal anti-acne moisturizer. Pak J Pharm Sci. 2012;25(4):867-70.

24. Patwardhan B, Datta HS, Mitra SK. Wound healing activity of topical application forms based on ayurveda. Evid Based Complement Altern Med. 2011.
25. Pimpare SS, Sonawane YT, Chaudhari CA, Sali LP, Jain NP, Gadgoli CH. Wound healing activity of topical application form based on herbomineral formulation. Asian J Plant Sci Res. 2012;2(3):355-63.

26. Jagtap NS, Khadabadi SS, Farooqui IA, Nalamwar VP, Sawarkar HA. Development and evaluation of herbal wound healing formulations. Int J Pharm Tech Res. 2009; 1(4):1104-8.

27. Nagar HK, Srivastava AK, Srivastava R, Kurmi ML, Chandel HS, Ranawat MS. Pharmacological investigation of the wound healing activity of Cestrum nocturnum (L.) ointment in Wistar albino rats. J Pharm. 2016.

28. Gangopadhyay KS, Khan M, Pandit S, Chakrabarti S, Mondal TK, Biswas TK. Pharmacological evaluation and chemical standardization of an ayurvedic formulation for wound healing activity. Int J Lower Extremity Wounds. 2014;13(1):419

29. Jha RK, Garud N, Nema RK. Excision and incision wound healing activity of flower head alcoholic extract of Sphaeranthus indicus Linn. in albino rats. Global J Pharm. 2009;3(1):32-7.

30. Nayak BS, Pereira LM. Catharanthus roseus flower extract has wound-healing activity in Sprague Dawley rats. BMC Complement Altern Med. 2006;6(1):41.

31. Kahn D, Spearman CW, Mall A, Shepherd E, Engelbrecht G, Lotz Z, et al. The effect of rapamycin on the healing of the ureteric anastomosis and wound healing. Transplantation Proceedings. 2005;37:830-1.

32. Prasad V. Evaluation of indigenous formulations for wound healing activity. M. Pharm Thesis, Nagpur University, Nagpur, India. 2002;35-7.

33. Biyani DM, Verma PRP, Dorle AK, Boxey V. Wound healing activity of cow ghee: A veterinary case report. Int J Ayurvedic Med. 2011:2(3):115-8.

Cite this article: Pratikcha R, Sujit D, Tanmoy G, Deveswaran R, Tanmay M, Kalyan R. Development of Sheep Butter Based Cream for Dermal Wound Healing. Int. J. Pharm. Investigation. 2020;10(1):43-8. 